\title{
Consumiendo: introducción al consumo y al consumidor colombiano
}

\section{Grupo de Investigación de Mercadeo I+2}

\author{
Reseña de autor \\ Grupo de Investigación de Mercadeo I+2: Alejandro Castaño Ramírez, Javier Darío Jiménez \\ Herrera, Leonardo Ortegón Cortázar, Oscar Javier Robayo Pinzón, Sandra Patricia Rojas Berrío \\ y Ricardo Arturo Vega Rodríguez.
}

\section{CONSUMIENDO}

Introducción al consumo y al consumidor Colombiano
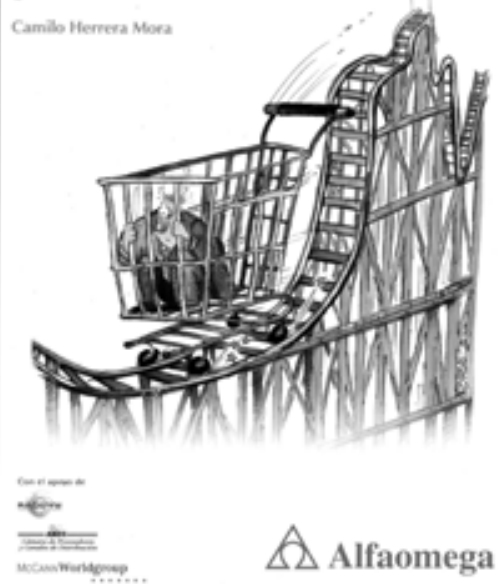

\section{Resumen}

En el libro Consumiendo. Introducción al consumo y al consumidor colombiano, su autor Camilo Herrera Mora, hace un esfuerzo por teorizar los comportamientos, percepciones, actitudes y creencias del consumidor colombiano, a partir de datos recolectados en investigaciones realizadas en diversos momentos y bajo diversos enfoques.

El libro explica elementos que describen la manera en que los colombianos consumimos. Uno de estos elementos es el cambio en las formas de compra: primero los formatos tradicionales, como las plazas de mercado; más tarde, las tiendas de barrio; y ahora los almacenes de grandes superficies, que se han instalado en nuestros hábitos, cambiándolos moderadamente. Esta tradición nos ha inculcado patrones 
de compra como la preferencia de las promociones, consideradas por el autor como formas del regateo.

Presenta resultados que ilustran los hábitos de consumo y las preferencias de los compradores colombianos en diferentes categorías de productos. También lleva a cabo una interpretación a partir de su experiencia como director de una reconocida empresa de investigación, para ubicar al lector en el contexto actual del consumidor colombiano.

Colombia presenta altos niveles de felicidad, según reflejan las estadísticas de algunos estudios internacionales sobre el tema, tratados en obra. El autor argumenta que esto se debe a que los colombianos se trazan objetivos muy bajos y, por lo tanto, cualquier logro, por pequeño que sea, eleva significativamente nuestro nivel de felicidad.

En el capítulo cuatro, el autor aborda se pregunta si todos los consumidores colombianos son iguales, y presenta resultados en relación con algunos aspectos del estilo de vida, como las actividades y los intereses -como hacer compras, estudiar, desempeñar labores domésticas. Tras este análisis, concluye que no existe un consumidor colombiano promedio, aunque se han identificado perfiles con claridad.

Con el ánimo de sustentar los resultados expuestos en el texto con algún modelo teórico específico, Herrera recurre de forma errática a modelos explicativos, basados en los conceptos necesidad, oportunidad y capacidad. Además, los combina con otros conceptos propios del neuromarketing, como cerebro reptil o cerebro límbico.

La obra resulta una lectura interesante para los interesados en el consumidor colombiano, pues constituye una forma muy buena de acercarse a la interpretación de resultados estadísticos que reflejan un conjunto de variables propias de la psicología del consumidor, así como variables usadas en la econometría.

El libro es un importante esfuerzo, que se puede asumir como una referencia inicial para la construcción de un conocimiento sustentado del comportamiento del consumidor colombiano. Sin embargo, sus argumentos se basan en datos aleatorios de diferentes investigaciones, con puntos de unión insuficientes, lo que genera conclusiones superficiales, sin procesos de corroboración posterior, que le aporten veracidad y pertinencia al contenido. 
Cuenta con un gran potencial para la población estudiantil de primeros semestres de programas de negocios, mercadeo, administración y ciencias sociales aplicadas, como la antropología, la psicología y la sociología, dado que define conceptos técnicos de las ciencias económicas de una manera muy clara para cualquier lector.

No obstante, la publicación presenta problemas como la ausencia de un componente sociocultural mucho más sólido; un estilo de escritura que carecerá de vigencia en unos años, dado que se incluyen expresiones como "en éste año" sin mencionar el periodo al que se refiere; e inconsistencias en las referencias bibliográficas: por un lado, se hacen afirmaciones sin especificar su fuente; y por otro, se mencionan autores sin su fuente respectiva, ni en el texto, ni en la lista de referencias.

\section{Referencias}

Herrera, (2010) Consumiendo: introducción al consumo y al consumidor colombiano. Bogotá: Alfaomega. 